keit erregt. Herr Dr. Goltdammer, dirigirender Arzt der inneren Abtheilung der Berliner Krankenanstalt Bethanien, gab in seinem Artikel "Leber die Kost- und Logirhäuser für die ärmercn Volksklassen ${ }^{\text {w }}$ (Vierteljahırschrift für gerichtliche Medicin etc. Bd. XXIX, S. 296) einen selır wichtigen Beitrag zur Kenntniss einer wahren Nachtseite Berlins, und der Rolle, welche jenc Häuser bei denı Ausbruche epidenischer Krankheiten spiclen und Gelı. Med.-Rath Prof. Skrzeczka, dessen unermüdlichem Eifer wir dic Einführung der Anzeigepflicht für Abdominaltyplius in Berlin verdanken, hat in demselben Archiv, Bd. XXX S. 143, auf diesc, dein Polizei-Präsidium darauf hin zugegangenen Anzeigen gestützt, den ersten Bericlit über die Typhus-Morbilität Berlins erstattet. Ehe wir aber auf beide Arheiten und einige andere Mittheilungen näher cingehen, mag es gestattet sein, zuvörderst das thatsächliche Material zu bringen, für dessen freundliche Mittheilung hiermit den Herren DDr. Skrzcczka und Cursclimann, dirigirendem Arzt des städtischen Barackenlazaretlscs, noch besonders gedankt sein soll.

Flecktyphus - Erkrankungen und Sterhefälle sind vom 1. Januar bis 31. März 1879 in Berlin gemeldet und zum allergrössten Theil dem Barackenlazarethe zugeführt worden:

Flecktyphus-Erkrankungen vom 1. Januar bis incl. 31. März 1879.

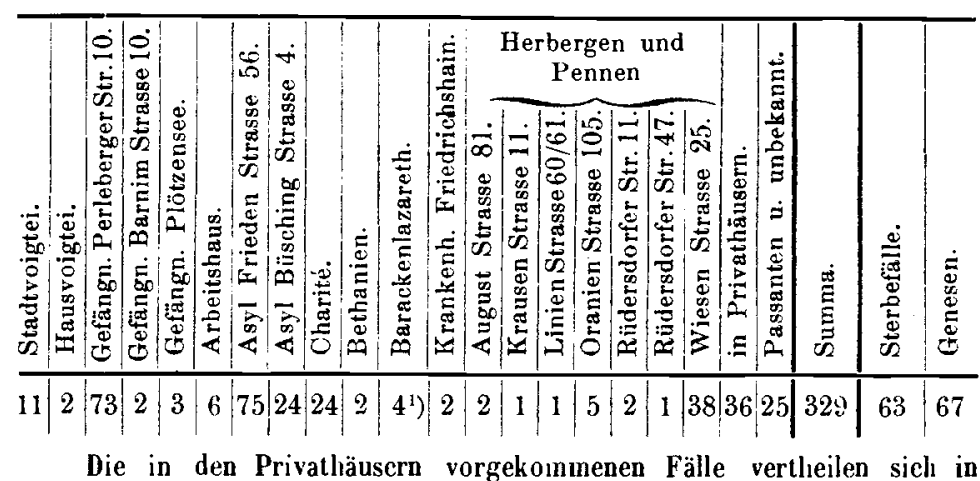

Die in den Privatläuscrn vorgekommenen Fälle vertheilen sich in folgender Weise:

Bad Strasse 421 Fall, Christinen Strasse 21 Fall, Dresdener Strasse 125 1 Fall, Fehrbelliner Strasse 561 Fall, Friedrichsfelder Strasse 281 Fall, Für sten Strasse 221 Fall, Georgenkirch Strasse 1 b. 2 Fälle, Hennigsdorfer Strasse 2 1 Fall, Höchste Strasse 471 Fall, Köpnicker Strasse 1392 Fälle, Lange Strasse 1091 Fall, Landsberger Strasse 451 Fall, Linien Strasse 60/61 1 Fall, Marcus Strasse 531 Fall, Oranlenburger Strasse 571 Fall, Pappel-Allee 28 1 Fall, Pappel-Allee 96 ' 1 Fall, Piickler Strasse 551 Fall, Reinickeridorfer Strasse 46 b. 1 Fall, Ritter Strasse 441 Fall, Schöneberger Strasse 51 Fall, Schönlein Strasse 51 Fall, Schumann Strasse 171 Fall, Skalitzer Strasse 36 1 Fall, Skalitzer Strasse 54 a. 5 Fälle (vor etwa 2 Monaten, seither kein neuer Fall), Stralsunder Strasse 81 Fall, Strelitzer Strasse 301 Fall, Teltower Strasse 401 Fall, Wall Strasse 161 Fall, Zehdenicker Strasse 141 Fall, in Summa 30 Häuser mit 36 Fâllen.

Im Barackenlazareth Moabit wurden im ersten Quartal 1879 aufgenommen 298 Flecktyphus-kranke Männer und 7 Flecktyphus-kranke Weiber, in Summa 305, einschliesslich der 4 in der Anstalt irificirten Wärter. Gestorben sind 47 Männer und 3 Weiber, in Summa 50 . Bestand Ende März mit den Reconvalescenten 130.

Die meisten dcm Barackenlazareth zugebrachten Kranken hatten vorher melirere Asyle, Penncn, Gefängnisse frequentirt. - Der Ort, wo die Infection erfolgt ist, bleibt meistens zweifelhaft.

Es sind meistens obdachlose Personen und es ist ziemlich zufälig, in welchem der Lokale, die sie fast alle passiren, dic Kranklieil constatirt und der Kranke angehalten und nach dem Krankenlaause befördert wird.

Gcnaue Erhebungen lassen nicht zu dem Schluss kommen, dass z. B. die Gefängnisse in der Perleberger Strasse Infectionsheerde sind d. h. dass gesunde Menschen dort durch den Einfluss der Oertliclıkeit erkranken. Dic Zahl der von dort in das Lazareth gelieferten Kranken beträgt 5 Proc. der Personen, dic seit dem 1. Januar in das Gefängniss gebracht sind. (Es ist für Abbüssung kurzer Haft, Polizeistrafen etc. bestimnıt.)

Die Penne in der Wiesen Strasse 25 ist die frequenteste, hat nächtlich bis 250 und mehr Gäste - die Zahl der Erkrankten, welclıe dort vorher genächtigt haben, ist demnach relativ nicht zu gross.

Diese Penne ist relativ gut, d. h. ein Gebäude, ursprüngliclı für Werkstätten bestimmt - grosse, lıelle, luftige Räume, ziemlielı reinlich - diese Pennen wie die andern dürfen nur bis zu 10 Cub.-Mtr. pro Kopf belegt werden - strenge Controle - daher Scliliessung bis jetzt als nich $t$ zwcckmässig befunden.

Die Privathäuser haben (mit 2 Ausnahuen) je nur einen Fall ge-

\section{Flecktyphus und Recurrens in Berlin während des ersten Quartals 1879.}

\section{I.}

Zwci Arbeiten zur öffentlichen Gesundheitspflege Berlins habcn in der neuesten Zeit mit Recht die anerkennende Aufmerksamhabt - Schlafburschen-Einlicger - also hat die Krankheit nirgend wo in denselben geeigneten Boden für dic Verbreitung gefunden. In einem Hause 5, in einem 2 Erkrankungen - directe Anstcckung, bcide vor mehren Wochen, laben sich also auch nicht zu Heerden entwickelt.

1) Diese 4 gehören zum Warte-Personal. 
Unter diesen Umständen muss man mit Herrn Skrzeczka zweifellos annehmen, dass eine Epidemie nicht vorlag.

Recurrens hat eine viel unbedeutendere Rolle gespielt, indessen ist es immerhin interessant, auch über sie die wenn auch nur kleinen Zalılen zu geben. Es wurden in dem Barackenlazareth 9 Fälle aufgenommen, die Ende März noch als Bestand vorhanden waren. Ueberhaupt wurden nach den V. d. K. D. Ges.-Amtes in den Berliner Krankenhäusern aufgenommen in der Woche vom 16.-22. Februar 1. 23. Februar - 1. März 8, 2.-8. März 2, 9.-15. März 2, 16.-22. März 6, 23.-29. März 3, also im Ganzen 22 Fälle, (wenn nämliclı durchweg die erste Diagnose bei der Anmeldung durch die spätere Beobachtung bestätigt sein sollte!) wobei der erste im Städtischen Krankenhaus im Friedrichshain vom Herrn Dr. Riess beobachtete Fall (diese W. No. 8. p. 85) nicht zugerechnet ist.

Bemerkt mag endlich noch werden, dass vom 1. Januar bis 26. März von Abdominaltyphus gemeldet worden sind 159 Erkrankungen mit 29 Todesfällen.

P. Boerner. 